\title{
COMPARISON OF SAGITTAL SPINAL CURVATURES AND PELVIC TILT IN HIGHLY TRAINED ATHLETES FROM DIFFERENT SPORT DISCIPLINES
}

\author{
Pedro A. López-Miñarro', Raquel Vaquero-Cristóbal², Fernando Alacid ${ }^{3}$, \\ Manuel Isorna ${ }^{4}$, and Jose M. Muyor ${ }^{5}$ \\ ${ }^{1}$ Department of Physical Education, University of Murcia, Spain \\ ${ }^{2}$ Chair of Sport Traumatology, Catholic University of Murcia, Spain \\ ${ }^{3}$ Department of Physical Activity and Sports, Catholic University of Murcia, Spain \\ ${ }^{4}$ Department of Physical Activity and Sports, University of Vigo, Spain \\ ${ }^{5}$ Laboratory of Kinesiology, Biomechanics and Ergonomics (KIBIOMER Lab.), \\ University of Almería, Spain
}

Original scientific paper

UDC: $61: 796.034 .6$

\begin{abstract}
:
The aim of this study was to compare the thoracic and lumbar curvatures and pelvic tilt in relaxed standing and maximal trunk flexion among highlytrained young athletes from three different sports disciplines. Thirty-two male canoeists, 30 male kayakers and 24 male tennis players were recruited for the study. The Spinal Mouse ${ }^{\circledR}$ system was used to measure the thoracic and lumbar sagittal spinal curvatures and pelvic tilt in relaxed standing and maximal trunk flexion in sitting with the flexed (McRae \& Wright test) and extended knees (sit-and-reach test). Significant differences were found in maximal trunk flexion tests among athletes. Kayakers and canoeists showed increased anterior pelvic tilt compared to tennis players in the McRae \& Wright $(\mathrm{p}<.01)$ and decreased posterior pelvic tilt in the sit-and-reach $(\mathrm{p}<.001)$ tests; however, canoeists had increased posterior pelvic tilt compared to kayakers in the sit-and-reach test $(p<.01)$. Canoeists had increased thoracic kyphosis curvature compared to kayakers $(p<.01)$ and tennis players $(p<.001)$ in the sit-and-reach test. Spinal sagittal curvatures and pelvic tilt in relaxed standing did not show significant differences. In conclusion, specific sports training may be associated with adaptations in the sagittal spinal curvatures and pelvic tilt when maximal trunk flexion positions are performed.
\end{abstract}

Key words: spine, thoracic curvature, lumbar curve, pelvic inclination, physical exercise

\section{Introduction}

Sagittal spinal curvatures are geometric parameters which influence mechanical properties and load balance of the intervertebral tissues (McGill, 2002). The spine is characterized by the presence of curvatures in a range of degrees which are considered normal (Santonja, Pastor, \& Serna, 2000). In some cases, an increase or decrease in magnitude of spinal curvatures may lead to spinal misalignment (McGill, 2002; Santonja, Pastor, \& Serna, 2000; Tüzün, Yorulmaz, Cindas, \& Vatan, 1999). The evolution of sagittal spine shape is influenced by several factors, which include intense athletic training. Exposure to intense athletic training over years may increase the risk of developing spinal disorders in athletes of certain sport disciplines (Dalichau \& Scheele, 2002; Grabara, 2012; Grabara,
\& Hadzik, 2009; López-Miñarro, Alacid, \& Rodriguez, 2010c; Mrozkowiak, Sokolowski, \& Kaiser, 2012; Muyor, López-Miñarro, \& Alacid, 2011b; Rajabi, Mobarakabadi, Alizadhen, \& Hendrick, 2012; Sokolowski, Kaiser, \& Mrozkowiak, 2013; Wojtys, Ashton-Miller, Huston, \& Moga, 2000). Wojtys et al. (2000) found a direct relationship between the amount of training and increased thoracic kyphosis and lumbar lordosis curvatures. Rajabi et al. (2012) showed a positive correlation between the years of training and thoracic kyphosis. Some changes in spinal curvatures may potentially influence the development of low-back disorders, which are common among athletes (McGill, 2002; Tüzün, et al., 1999).

Each sport discipline is unique because it involves specific postures and movements during 
training and competition (López-Miñarro, Muyor, Alacid, \& Rodriguez, 2011b). Some sports are characterized by trunk flexion postures while sitting, for example, cycling, kayaking or rowing (López-Miñarro, \& Alacid, 2010a, 2010b; LópezMiñarro, Alacid, Ferragut, \& García, 2008; LópezMiñarro, et al., 2010c; López-Miñarro, Muyor, \& Alacid, 2010d; Muyor, Alacid, \& López-Miñarro, 2011a; Muyor, et al., 2011b; Muyor, Alacid, LópezMiñarro, \& Casimiro, 2012a; Muyor, Vaquero-Cristóbal, Alacid, \& López-Miñarro, 2014) or kneeling, for instance, canoeing (López-Miñarro, \& Alacid, 2010a, 2010b; López-Miñarro, et al., 2008, 2010c; López-Miñarro, Muyor, \& Alacid, 2011a; Muyor, et al., 2014). Other sports involve a slight trunk flexion combined with extension and rotational trunk movements while standing, such as tennis (Dalichau, \& Scheele, 2002; Muyor, Sánchez-Sánchez, Sanz-Rivas, \& López-Miñarro, 2013; Muyor, et al., 2014), table tennis (Barczyk-Pawelec, Bánkosz \& Derlich, 2012), handball (Grabara, 2014a, 2014b), volleyball (Grabara, 2014b, 2015), basketball (Grabara, 2014b), football (Grabara, 2012), wrestling (Mrozkowiak, et al., 2012; Rajabi, Doherty, Goodarzi, \& Hemayattalab, 2007; Sokolowski, et al., 2013) or field hockey (Rajabi, et al., 2012). These differences in spinal postures may induce specific modifications in spinal curvatures when training for long periods (Wojtys, et al., 2000).

Kayaking is characterized by a bilateral paddle technique which induces symmetrical and bilateral trunk movements and spine inclination in the transverse plane (Cox, 1992). Kayakers sit with their knees almost extended in a slight lumbar kyphosis posture for long training periods (López-Miñarro, et al., 2010d; López-Miñarro, et al., 2013). This prolonged flexion posture in the boat can induce adaptations such as creep deformation in viscoelastic tissues (López-Miñarro \& Alacid, 2010a; McGill, \& Brown, 1992; Shin, \& Mirka, 2007; Toosizadeh, Nussbaum, Bazrgari, \& Madigan, 2012), defined as the tendency of human soft tissues (tendons, ligaments, muscles, etc.), which have viscoelastic properties and, as a consequence, are highly deformable, to move slowly or deform permanently under the influence of mechanical stresses (McGill \& Brown, 1992). Creep in trunk viscoelastic tissues induces a decrease in trunk joint stiffness (McGill \& Brown, 1992) and, as a consequence, elevated spine mobility. These relationships may be partly explained by the fact that previous studies have found increased lumbar flexion angles in the maximal trunk flexion with the extended knees (López-Miñarro \& Alacid, 2010a; Muyor, et al., 2014) and increased thoracic kyphosis in relaxed standing in kayakers (LópezMiñarro \& Alacid, 2010a; López-Miñarro, et al., 2008, 2010c, 2010d; Muyor, et al., 2011a). However, kayakers have showed neutral lumbar lordosis in relaxed standing (López-Miñarro \& Alacid, 2010a; López-Miñarro, et al., 2008, 2010c, 2010d; Muyor, et al., 2011a).

The discipline of canoeing involves postures and movements different from kayaking. Canoeing is characterized by a kneeling position in the canoe, with one knee on a knee brace (kneeling leg) on the lower part of the craft and the other leg located at the front of the canoe (forward leg), and stroking with the paddle on the side of the kneeling leg of the boat. It involves a cyclic action of the upper segments of the body combined with cyclic trunk movements of flexion, rotation and lateral inclination (LópezMiñarro, et al., 2013). López-Miñarro et al. (2008) found a high frequency of thoracic hyperkyphosis in canoeists while standing and hypothesized that this spinal posture might be associated with the posture assumed during training. However, another study showed that the thoracic curvature caused during paddling in canoeing is decreased compared with the thoracic angle in relaxed standing (LópezMiñarro, et al., 2011a).

In contrast to the paddling disciplines, tennis is an acyclic and one-sided racquet sport with a predominance of fast flexion, extension and rotation trunk movements in the sagittal and frontal planes in erect postures (Dalichau \& Scheele, 2002; Muyor, et al., 2013, 2014). Repetitive, strenuous and intensive training may generate adaptations in spinal morphology (López-Miñarro, Muyor, Belmonte, \& Alacid, 2012; McGill \& Brown, 1992; Shin \& Mirka, 2007). However, previous studies have reported that tennis players show normal thoracic and lumbar curvatures in standing (Dalichau \& Scheele, 2002; Muyor, et al., 2013), whereas differences in pelvic tilt were detected between senior tennis players and recreational athletes (Dalichau \& Scheele, 2002). Nevertheless, data on sagittal spinal morphology in tennis players in other postures, for example, maximal trunk flexion positions, are limited.

Because specific positions and movements during training and competition can generate different adaptations in spinal and pelvic postures, the aim of this study was to compare the thoracic and lumbar curvatures and pelvic tilt in relaxed standing and maximal trunk flexion among kayakers, canoeists and tennis players.

\section{Methods}

\section{Participants}

Thirty-two male canoeists $(\mathrm{M} \pm \mathrm{SD}$ age: $17.09 \pm 2.93$ years; body height: $170.69 \pm 9.42 \mathrm{~cm}$; body mass: $69.80 \pm 11.21 \mathrm{~kg}$ ), 30 male kayakers (age: $16.47 \pm 2.89$ years; body height: $171.56 \pm 20.78$ $\mathrm{cm}$; body mass: $74.30 \pm 21.31 \mathrm{~kg}$ ) and 24 male 
tennis players (age: $15.75 \pm 1.42$ years; body height: $174.91 \pm 10.08 \mathrm{~cm}$; body mass: $67.19 \pm 10.93 \mathrm{~kg}$ ) were recruited for the study. The inclusion criteria were more than four years of regular training with a frequency of at least five times per week, with more than 90 minutes in each session. Athletes were excluded if they presented pain induced or exacerbated by the test procedures, injury preventing participation in training before testing or known structural spinal pathology.

\section{Procedures}

This study was approved by the Institutional Ethical Committee. All subjects and parents or legal guardians signed an informed consent form before participation. The Spinal Mouse ${ }^{\circledR}$ system (Idiag, Fehraltdorf, Switzerland), a hand-held computerassisted electromechanical-based device, was used to measure sagittal spinal curvatures and pelvic inclination in a relaxed standing position and maximal trunk flexion in sitting with the flexed (Macrae \& Wright test) and extended knees (sit-and-reach test). The measurements were made in random order. The subjects were allowed to rest briefly, standing up for 5 minutes between measurements. All measurements were made during the same testing session and were administered in a temperature-controlled laboratory under the same environmental conditions $\left(24^{\circ} \mathrm{C}\right)$. Participants were instructed not to undertake a weight-training session or strenuous exercise 24 hours before testing.

Prior to measurement, the principal researcher determined the seventh cervical spinous process $\left(\mathrm{C}_{7}\right.$; starting point) and the top of the anal crease (end point) by palpation and marked these on the participants' skin with a pencil. The Spinal Mouse ${ }^{\circledR}$ was guided along the midline of the spine (or slightly paravertebrally in particularly thin individuals with prominent spinous processes) starting at the spinous process of $\mathrm{C}_{7}$ and finishing at the top of the anal crease (approximately at the third sacral spinous process). For each testing position, the thoracic (from the first or second to the eleventh or twelfth thoracic spinous process) and lumbar spine (from the twelfth thoracic or first lumbar spinous process to the sacrum) and the pelvic inclination (difference between the sacral angle and the vertical axis) were recorded. In thoracic and lumbar curvatures, positive values corresponded to kyphotic curves (concave anteriorly and convex posteriorly) and negative values corresponded to lordotic curves (convex anteriorly and concave posteriorly). With respect to the pelvic inclination, a value of $0^{\circ}$ represented the vertical position. Thus, an increase in the angle reflected an anterior pelvic tilt while a decrease in the angle (negative values) reflected a posterior pelvic tilt.

\section{Postures}

\section{Relaxed standing}

The subject assumed a relaxed position, with the head facing forward, the arms hanging by the side, the knees normally extended, and the feet shoulderwidth apart (Figure 1).

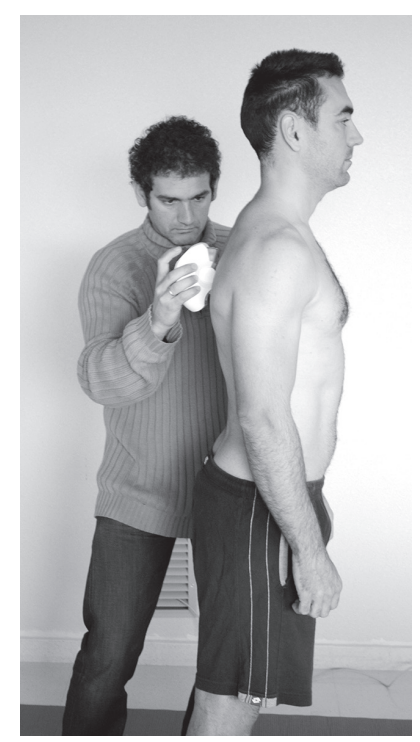

Figure 1. Spinal curvatures and pelvic tilt measured in the relaxed standing position.

Maximal trunk flexion in sitting with the flexed knees (Macrae \& Wright test)

The subject sat on a chair with his both knees flexed at $90^{\circ}$. They were asked to slowly bend their trunk as far as possible, aiming to curl the head into the knees (Macrae \& Wright, 1969). Spinal angles and pelvic tilt were measured when the subject reached the maximal trunk flexion (Figure 2).

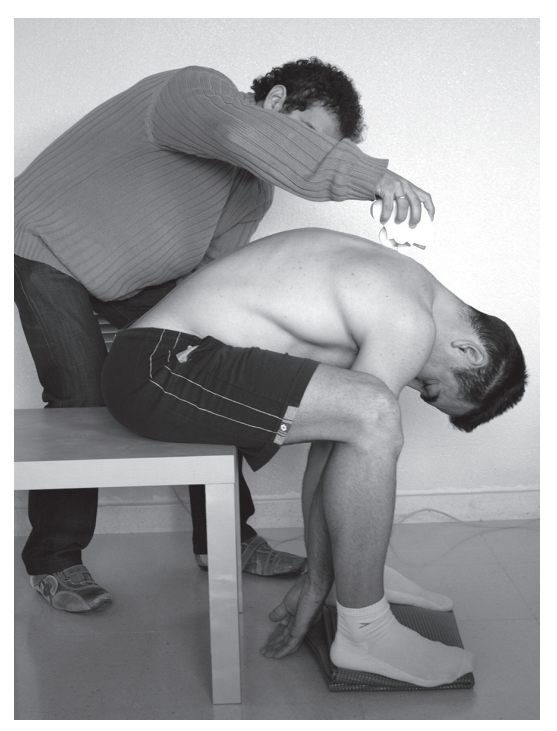

Figure 2. Spinal curvatures and pelvic tilt measured during maximal trunkflexion in sitting with the flexed knees (Macrae $\&$ Wright test). 
Maximal trunkflexion with the extended knees (sitand-reach test)

The participant was required to sit with his knees straight and legs together so that the soles of the feet were flat against the end of a sit-and-reach box (height $=32 \mathrm{~cm}$ ). With palms down, the subject placed one hand on top of the other and slowly reached forward as far as possible. The subject slid his hands along the box, with his knees kept as straight as possible and held the resulting position for approximately five seconds while the spinal curvatures and pelvic inclination were measured (Figure 3).

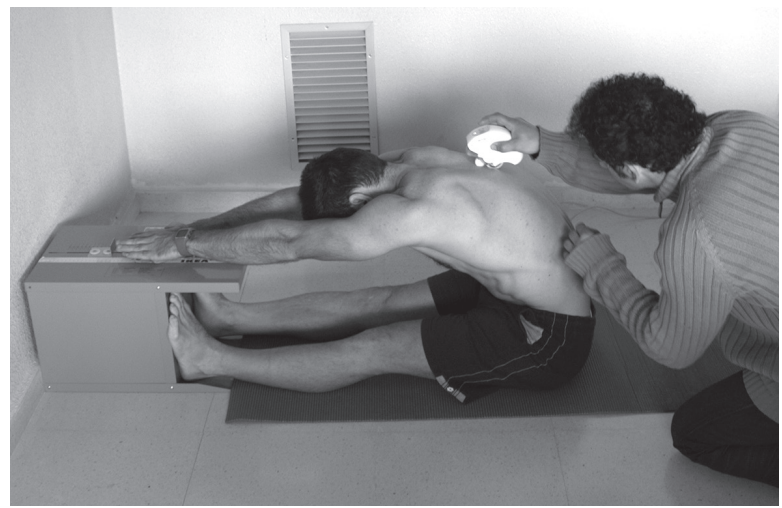

Figure 3. Spinal curvatures and pelvic tilt measured during maximal trunk flexion in sitting with the extended knees (sit-and-reach test).

\section{Data analysis}

The hypothesis of data normality was analysed via the Shapiro-Wilk test. Descriptive statistics including means and standard deviations were calculated. One-way analysis of variance (ANOVA) was used to detect differences among the groups in the postures evaluated for the lumbar and thoracic curvatures and pelvic tilt. The level of significance was set $a$ priori at $\mathrm{p} \leq .05$. If a significant $\mathrm{p}$-value was identified for the main effect, pairwise comparisons were made using the Bonferroni correction for multiple comparisons with the significance criterion adjusted to $\mathrm{p}<.016$. The data were analysed using the SPSS v. 19.0 .

\section{Results}

The $\mathrm{M} \pm \mathrm{SD}$ and the significant differences of the thoracic and lumbar curves and pelvic tilt in different positions are presented in Table 1 . No significant differences were found in the relaxed standing position among the groups $\left(\mathrm{F}_{(2,83)}=.337\right.$, $\mathrm{p}=.715$ thoracic curve; $\mathrm{F}_{(2,83)}=1.577, \mathrm{p}=.213$ lumbar curve; and $\mathrm{F}_{(2,83)}=.249, \mathrm{p}=.780$ pelvic tilt). In the Macrae \& Wright test, significant differences were found in the pelvic tilt $\left(\mathrm{F}_{(2,83)}=7.098, \mathrm{p}=.001\right)$. Tennis players showed decreased anterior pelvic tilt in respect to canoeists and kayakers $(\mathrm{p}<.01)$. However, no significant differences were found in the thoracic or lumbar curvatures $\left(\mathrm{F}_{(2,83)}=2.260, \mathrm{p}=.111\right.$ and $\mathrm{F}_{(2,83)}=.764, \mathrm{p}=.469$, respectively). In the sit-andreach test, the ANOVA analysis revealed significant differences in thoracic curve $\left(\mathrm{F}_{(2,83)}=14.144\right.$, $\mathrm{p}<.001)$. Canoeists showed significantly increased thoracic kyphosis compared to kayakers $(p<.01)$ and tennis players $(p<.001)$. No significant differences were found between the groups for the lumbar curvature $\left(\mathrm{F}_{(2,83)}=2.082, \mathrm{p}=.131\right)$. With regard to pelvic tilt, significant differences among disciplines were found $\left(\mathrm{F}_{(2,83)}=10.833, \mathrm{p}<.001\right)$. Tennis players had significantly increased posterior pelvic tilt compared to canoeists and kayakers $(\mathrm{p}<.001)$, whereas kayakers showed a position near the vertical pelvic tilt $(\mathrm{p}<.01$ respect canoeists).

Table 1. Mean values ( \pm standard deviation) and significant differences of the spinal curvatures and pelvic inclination while adopting relaxed standing and trunk flexion positions in different groups

\begin{tabular}{|c|c|c|c|}
\hline & CANOEISTS & KAYAKERS & TENNIS PLAYERS \\
\hline \multicolumn{4}{|c|}{ Relaxed standing } \\
\hline Thoracic curvature & $45.56 \pm 8.40^{\circ}$ & $44.50 \pm 7.61^{\circ}$ & $43.83 \pm 7.87^{\circ}$ \\
\hline Lumbar curvature & $-30.28 \pm 7.67^{\circ}$ & $-27.27 \pm 7.06^{\circ}$ & $-27.58 \pm 7.01^{\circ}$ \\
\hline Pelvic tilt & $14.34 \pm 5.24^{\circ}$ & $14.10 \pm 4.82^{\circ}$ & $13.38 \pm 5.57^{\circ}$ \\
\hline \multicolumn{4}{|c|}{ Macrae \& Wright test } \\
\hline Thoracic curvature & $70.78 \pm 11.37^{\circ}$ & $70.03 \pm 9.96^{\circ}$ & $65.25 \pm 8.74^{\circ}$ \\
\hline Lumbar curvature & $31.44 \pm 8.31^{\circ}$ & $33.97 \pm 8.10^{\circ}$ & $33.58 \pm 9.62^{\circ}$ \\
\hline Pelvic tilt & $49.94 \pm 9.21^{\circ}$ * & $49.30 \pm 8.21^{\circ *}$ & $42.33 \pm 6.01^{\circ}$ \\
\hline \multicolumn{4}{|c|}{ Sit-and-reach test } \\
\hline Thoracic curvature & $70.88 \pm 8.03^{\circ} \dagger$ & $62.17 \pm 12.35^{\circ * *}$ & $57.38 \pm 7.78^{\circ}$ \\
\hline Lumbar curvature & $27.97 \pm 6.95^{\circ}$ & $32.20 \pm 8.02^{\circ}$ & $30.67 \pm 9.99^{\circ}$ \\
\hline Pelvic tilt & $-13.50 \pm 4.95^{\circ} \dagger$ & $-6.80 \pm 2.64^{\circ * *} \dagger$ & $-17.08 \pm 3.29^{\circ}$ \\
\hline
\end{tabular}

Note. ${ }^{*} p<.01$ with respect to tennis players; ${ }^{* *} p<.01$ with respect to canoeists; $\dagger p<.001$ with respect to tennis players. 


\section{Discussion and conclusions}

The main objective of the present study was to compare the thoracic and lumbar curvatures and pelvic tilt among athletes of different sport disciplines (canoeing, kayaking and tennis). The spine has physiological curvatures in the sagittal plane, which can be classified as neutral or normal, hyperlordotic (increased lordotic curvature), hypolordotic (decreased lordotic curvature), hyperkyphotic (increased kyphotic curvature), or hypokyphotic curvatures (decreased kyphotic curvature) based on age (Santonja, et al., 2000). However, specific positions and movements during training and competition can generate different adaptations in spinal and pelvic postures. One interesting finding was that no significant differences in relaxed standing were detected in any variable among the observed male athletes. The thoracic angles were slightly increased compared to the values considered as neutral thoracic kyphosis, whereas lumbar lordosis and pelvic tilt were within the range of angles considered as normal values in adolescents as measured by X-Ray (Santonja, et al., 2000). These measurements show a high correlation with the measurements carried out using the Spinal Mouse ${ }^{\circledR}$ (Guermazi, et al., 2006). Previous studies, involving adolescents and/or adults male paddlers (López-Miñarro \& Alacid, 2010a, 2010b; LópezMiñarro, et al., 2008, 2010c, 2010d, 2011a; Muyor, et al., 2011a), male tennis players (Dalichau \& Scheele, 2002; Muyor, et al., 2013) and other male athletes who train in flexion postures while standing, such as table tennis players (Barczyk-Pawelec, et al., 2012), field hockey players (Rajabi, et al., 2012), volleyball players (Grabara, 2014b, 2015), or cyclists (Muyor, et al., 2011b, 2012a), have found similar results when standing posture have been evaluated. Furthermore, in standing no significant differences were detected for the pelvic tilt and mean values were consistent with previously published normative data in young paddlers (López-Miñarro, et al., 2010d, 2011a) and tennis players (Muyor, et al., 2013).

The analysis of the sagittal spinal curvatures should be performed whilst the subject adopts several positions. Trunk flexion postures are habitual positions in sport training (Grabara, 2012; López-Miñarro \& Alacid, 2010a, 2010b; LópezMiñarro, et al., 2008, 2010c, 2010d, 2011a; Mrozkowiak, et al., 2012; Muyor, et al., 2011a, 2011b, 2012a, 2014; Rajabi, et al., 2007, 2012; Sokolowski, et al., 2013). As hamstring muscles influence spinal curvatures and pelvic tilt during trunk flexion with the knees extended (López-Miñarro \& Alacid, 2010b; López-Miñarro, et al., 2010c, 2013; Muyor, Alacid, Rodríguez-Garcia, \& López-Miñarro, 2012b; Muyor, et al., 2014), the analysis of spinal curves during trunk flexion with the knees both extended and flexed is suitable.
Several differences were found in the trunk flexion tests. Pelvic inclination showed a posterior pelvic tilt in all groups in the sit-and-reach test, although kayakers and canoeists showed pelvic tilt nearer to the neutral position than tennis players. When the knees are flexed and a maximal trunk bending is required (Macrae \& Wright test), athletes showed anterior pelvic tilt. The comparison among the groups suggests increased anterior pelvic tilt in kayakers and canoeists with respect to tennis players in both tests. This could be explained by the characteristics of sport-specific training position and movements. Firstly, the pelvis has a high range of movement in canoeing and kayaking (LópezMiñarro, et al., 2010d, 2011a, 2013). Secondly, kayaking and canoeing are characterized by pronounced trunk flexion positions with movements in the sagittal and transverse planes (Cox, 1992; López-Miñarro, et al., 2010d, 2013). As paddlers spend a large amount of time training in their boats in the flexed postures (López-Miñarro \& Alacid, 2010a), they may suffer a high creep deformation in spinal viscoelastic tissues, which induces an increase in spine and pelvic tilt mobility (McGill \& Brown, 1992; Shin \& Mirka, 2007; Toosizadeh, et al., 2012). Conversely, tennis players adopt a more erect posture with fast trunk movements in both directions in the sagittal and frontal plane and rotational movements around the long axis (Dalichau \& Scheele, 2002; Muyor, et al., 2013, 2014), which are not related to creep deformation in viscoelastic tissues (McGill \& Brown, 1992; Shin \& Mirka, 2007; Toosizadeh, et al., 2012). It is possible, therefore, that paddlers achieve increased anterior pelvic tilt positions in the Macrae \& Wright test as a consequence of a high creep deformation in spinal viscoelastic tissues.

When the thoracic curvature in maximal trunk flexion tests was analysed, similar thoracic curves in the Macrae \& Wright test were found among the groups. The Macrae \& Wright test is performed with the knees flexed to $90^{\circ}$, thus minimizing the tension stimulus of the hamstrings during maximal trunk flexion. An increased thoracic curve has been associated with decreased hamstring extensibility when maximal trunk flexion with the knees extended is performed (López-Miñarro \& Alacid, 2010b; Muyor, et al., 2012b, 2014). However, when maximal trunk flexion is performed with the knees flexed, the anterior pelvic tilt is increased and hamstring extensibility plays a minimum role in the lumbar and thoracic postures.

Trunk flexion measurement with the extended knees is very important in determining the influence of hamstring muscles on spinal postures. When the sit-and-reach test was performed, some differences among the sport disciplines were detected. Canoeists showed significantly increased thoracic kyphosis 
curvatures compared to kayakers. The current study did not measure hamstring extensibility with any angular test (knee extension or straight leg raise tests). However, previous studies have found that canoeists showed decreased hamstring extensibility compared to adolescent kayakers (Muyor, et al., 2014). Decreased hamstring extensibility has been associated with increased thoracic kyphosis curvatures in the sit-and-reach test (López-Miñarro \& Alacid, 2010b; Muyor, et al., 2012b, 2014). Another important finding was that tennis players presented decreased thoracic kyphosis curves in the sit-andreach test compared to paddlers, with significant differences between canoeists and tennis players. Differences between these disciplines could be related to hamstring extensibility as well as the differing postures and movements of each sport. Kayak and canoe involve cyclic and static flexion postures, respectively (López-Miñarro, et al., 2010d, 2013). Increased creep deformation in spinal viscoelastic tissues, decreased trunk joint stiffness and increased spine mobility in flexion postures could be associated with prolonged flexion posture in the boat (López-Miñarro \& Alacid, 2010a; McGill \& Brown, 1992; Shin \& Mirka, 2007; Toosizadeh, et al., 2012).

The pelvis lies below the lumbar spine and the sacroiliac joint connects both. Therefore, there is a direct relationship between pelvic posture and lumbar curvature (López-Miñarro, et al., 2014). However, the current study found that no significant differences were detected in the lumbar curves in the trunk flexion tests among athletes. Previous studies have found similar results among young kayakers, canoeists, tennis players and cyclists in the sit-and-reach test (López-Miñarro, et al., 2014;
Muyor, et al., 2014). Furthermore, no previous study has investigated the differences among different athletes in the Macrae \& Wright test. It was hypothesized that participants did not show significant differences in lumbar curvature because longer training periods are needed in order to suffer adaptations (around 400 hour/year of training) (Wojtys, et al., 2000). The sample of the current study had trained fewer hours. Further studies should analyse the relationship between training hours per year and spinal adaptations across several sport disciplines. One limitation of the present research is that some of previous papers have analysed adult athletes. Sagittal spine curvatures and pelvic inclination are different in adolescents and adults (Ghandhari, Hesarikia, Ameri, \& Noori, 2013). Therefore, these comparisons may be somewhat limited due to the differences in the age of participants. The study of spine disposition in athletes of different ages or the development of spine disposition comparing athletes and sedentary subjects during periods of growth is an important issue for future research.

Specific postures and movements during specific sport training were associated with adaptations in sagittal spinal curvatures and pelvic tilt in maximal trunk flexion positions. In addition, canoeists and kayakers have showed increased pelvic tilt and/or increased thoracic kyphosis curves in the maximal trunk flexion tests with the flexed and extended knees in comparison to tennis players. This is a consequence of a prolonged trunk flexion posture and a higher range of movement of the spine and pelvis in paddlers. Training does not affect spinal and pelvic posture in relaxed standing and lumbar disposition in the maximal trunk flexion test.

\section{References}

Barczyk-Pawelec, K., Bańkosz, Z., \& Derlich, M. (2012). Body postures and asymmetries in frontal and transverse planes in the trunk area in table tennis players. Biology of Sport, 29, 129-134.

Cox, R.W. (1992). The science of canoeing. Cheshire: Coxburn Press.

Dalichau, S., \& Scheele, K. (2002). Influence of sports mechanic demands in competitive tennis on the thoracolumbar spinal profile. Sportverletz Sportschaden, 16(2), 64-69.

Ghandhari, H., Hesarikia, H., Ameri, E., \& Noori, A. (2013). Assessment of normal sagittal alignment of the spine and pelvis in children and adolescents. BioMed Research International, 842624, 1-7. doi: 10.1155/2013/842624

Grabara, M. (2012). Analysis of body posture between young football players and their untrained peers. Human Movement, 13(2), 120-126.

Grabara, M. (2014a). A comparison of the posture between young female handball players and non-training peers. Journal of Back and Musculoskeletal Rehabilitation, 27(1), 85-92.

Grabara, M. (2014b). Anteroposterior curvatures of the spine in adolescent athletes. Journal of Back and Musculoskeletal Rehabilitation, 27(4), 513-519.

Grabara, M. (2015). Comparison of posture among adolescent male volleyball players and non-athletes. Biology of Sport, 32(1), 79-85.

Grabara, M., \& Hadzik, A. (2009). The body posture in young athletes compared to their peers. Medycyna Sportowa, $2(6), 115-124$. 
Guermazi, M., Ghroubi, S., Kassis, M., Jaziri, O., Keskes, H., Kessomtini, W., et al. (2006). Validity and reliability of Spinal Mouse ${ }^{\circledR}$ to assess lumbar flexion. Annales de Réadaptation et de Médecine Physique, 49(4), 172-177.

López-Miñarro, P.A., \& Alacid, F. (2010a). Cifosis funcional y actitud cifótico lumbar en piragüistas adolescentes. [Functional kyphosis and lumbar kyphosis in adolescent paddlers. In Spanish.] Retos. Nuevas Tendencias en Educación Física, Deporte y Recreación, 17(1), 5-9.

López-Miñarro, P.A., \& Alacid, F. (2010b). Influence of hamstring muscle extensibility on spinal curvatures in young athletes. Science and Sport, 25(4), 188-193.

López-Miñarro, P.A., Alacid, F., Ferragut, C., \& García, A. (2008). Valoración y comparación de la disposición sagital del raquis entre canositas y kayakistas de categoría infantil. [Measurement and comparison of sagittal spinal curvatures between infantile canoeists and kayakers. In Spanish.] Cultura, Ciencia y Deporte, 3(9), 171-176.

López-Miñarro, P.A., Alacid, F., \& Rodríguez, P.L. (2010c). Comparison of sagittal spinal curvatures and hamstring muscle extensibility among young elite paddlers and non-athletes. International SportMed Journal, 11(2), 301-312.

López-Miñarro, P.A., Muyor, J.M., \& Alacid, F. (2010d). Sagittal spinal curvatures and pelvic tilt in elite young kayakers. Medicina dello Sport, 63(4), 509-519.

López-Miñarro, P.A., Muyor, J.M., \& Alacid, F. (2011a). Sagittal spinal and pelvic postures of high-trained young canoeists. Journal of Human Kinetics, 29, 41-48.

López-Miñarro, P.A., Muyor, J.M., Alacid, F., \& Rodríguez, P.L. (2011b). Influence of sport training on sagittal spinal curvatures. In A.M. Wright \& S.P. Rothenberg (Eds.), Posture: Types, assessment and control (pp. 63-98). New York: Nova Publishers.

López-Miñarro, P.A., Muyor, J.M., Alacid, F., \& Vaquero-Cristóbal, R. (2014). Influence of hamstring extensibility on spinal and pelvic postures in highly trained athletes. In S.A. Curran (Ed.), Posture: Types, exercises and health effects (pp. 81-93). New York: Nova Publishers.

López-Miñarro, P.A., Muyor, J.M., Alacid, F., Vaquero-Cristóbal, R., López-Plaza, D., \& Isorna, M. (2013). Comparison of hamstring extensibility and spinal posture between kayakers and canoeists. Kinesiology, 45(2), 163-170.

López-Miñarro, P.A., Muyor, J.M., Belmonte, F., \& Alacid, F. (2012). Acute effects of hamstring stretching on sagittal spinal curvatures and pelvic tilt. Journal of Human Kinetics, 31, 69-78.

Macrae, I.F., \& Wright, V. (1969). Measurements of low back movement. Annals of the Rheumatic Diseases, 28(6), 584-589.

McGill, S.M. (2002). Low back disorders. Evidence-based prevention and rehabilitation. Champaign, IL: Human Kinetics.

McGill, S.M., \& Brown, S. (1992). Creep response of the lumbar spine to prolonged full flexion. Clinical Biomechanics, 7(1), 43-46.

Mrozkowiak, M., Sokolowski, M., \& Kaiser, A. (2012). Characteristics of habitual posture in female wrestlers from the Polish National Team. Medicina dello Sport, 65(2), 235-251.

Muyor, J.M., Alacid, F., \& López-Miñarro, P.A. (2011a). Morfología Sagital del Raquis en Palistas Jóvenes de Alto Nivel. [Sagittal spinal in young highly-trained paddlers. In Spanish.] International Journal of Morphology, 29(3), 1047-1053.

Muyor, J.M., Alacid, F., López-Miñarro, P.A., \& Casimiro, A.J. (2012a). Evolución de la Morfología del Raquis e Inclinación Pélvica en Ciclistas de Diferentes Edades. Un Estudio Transversal. [Evolution of spinal morphology and pelvic tilt in cyclists of different ages. A cross-sectional study. In Spanish.] International Journal of Morphology, 30(1), 199-204.

Muyor, J.M., Alacid, F., Rodríguez-García, P.L., \& López-Miñarro, P.A. (2012b). Influencia de la extensibilidad isquiosural en la morfología sagital del raquis e inclinación pélvica en deportistas. [Influence of hamstring extensibility on sagittal spinal curvatures and pelvic inclination in athletes. In Spanish.] International Journal of Morphology, 30(1), 176-181.

Muyor, J.M., López-Miñarro, P.A., \& Alacid, F. (2011b). Spinal posture of thoracic and lumbar spine and pelvic tilt in highly trained cyclists. Journal of Sports Science and Medicine, 10, 355-361.

Muyor, J.M., Sánchez-Sánchez, E., Sanz-Rivas, D., \& López-Miñarro, P.A. (2013). Sagittal spinal morphology in highly trained adolescent tennis players. Journal of Sports Science and Medicine, 12, 588-593.

Muyor, J.M., Vaquero-Cristóbal, R., Alacid, F., \& López-Miñarro, P.A. (2014). Criterion-related validity of sit-and-reach and toe-touch tests as a measure of hamstring extensibility in athletes. Journal of Strength and Conditioning Research, 28(2), 546-555.

Rajabi, R., Doherty, P., Goodarzi, M., \& Hemayattalab, R. (2007). Comparison of thoracic kyphosis in two groups of elite Greco-Roman and free style wrestlers and a group of non-athletic subjects. British Journal of Sport Medicine, 42(3), 229-232.

Rajabi, R., Mobarakabadi, L., Alizadhen, H.M., \& Hendrick, P. (2012). Thoracic kyphosis comparisons in adolescent female competitive field hockey players and untrained controls. Journal of Sports Medicine and Physical Fitness, 52(5), 545-550.

Santonja, F., Pastor, A., \& Serna, L. (2000). Valoración radiográfica de las desalineaciones sagitales del raquis. [X-ray diagnosis of sagittal alignment of spine. In Spanish.] Selección, 9(4), 216-229. 
Shin, G., \& Mirka, G.A. (2007). An in vivo assessment of the low back response to prolonged flexion: Interplay between active and passive tissues. Clinical Biomechanics, 22(9), 965-971.

Sokolowski, M., Kaiser, A., \& Mrozkowiak, M. (2013). Body posture in female wrestlers before and after specialized physical training. Medicina dello Sport, 66(4), 473-484.

Toosizadeh, N., Nussbaum, M.A., Bazrgari, B., \& Madigan, M.L. (2012). Load-relaxation properties of the human trunk in response to prolonged flexion: Measuring and modeling the effect of flexion angle. PLoS One, 7(11), e48625.

Tüzün, C., Yorulmaz, I., Cindas, A., \& Vatan, S. (1999). Low back pain and posture. Clinical Rheumatology, 18(4), 308-312.

Wojtys, E., Ashton-Miller, J., Huston, L., \& Moga, P. (2000). The association between athletic training time and sagittal curvature of the immature spine. The American Journal of Sports Medicine, 28(4), 490-498.

Submitted: March 11, 2015

Accepted: October 12, 2016

Correspondence to:

Raquel Vaquero-Cristóbal

Chair of Sport Traumatology,

Catholic University San Antonio of Murcia

University Campus of the Jerónimos s/n. CP.

30107 Guadalupe, Murcia, Spain

Phone: +34 968278 655;

E-mail: rvaquero@ucam.edu 